\title{
PENGENALAN BAHASA INGGRIS DAN LIFE SKILLS MELALUI KEGIATAN BERCERITA DI RA ESA GLOBAL INSANI
}

\author{
Fitria Iswari ${ }^{1}$, Herliyana Rosalinda ${ }^{2}$, Widya Nuriyanti ${ }^{3}$ \\ Program Studi Desain Komunikasi Visual \\ Fakultas Bahasa dan Seni, Universitas Indraprasta PGRI \\ Jl. Nangka 58 Tanjung Barat, Jakarta Selatan
}

\begin{abstract}
Abstrak
Bahasa Inggris dalam era globalisasi seperti sekarang ini menjadi bahasa yang sudah tidak asing lagi bagi anak - anak masa kini. Bahasa Inggris adalah bahasa pengantar yang sering digunakan dalam berbagai kegiatan. Begitupula dengan gawai, terkadang alat ini mampu menggantikan kebiasaan yang sering dilakukan orang tua dengan anak, contohnya : dahulu anak menunggu orang tua untuk dibacakan dongeng atau cerita sebelum tidur dengan buku - buku bacaan mereka, sekarang ini mereka bisa mendengarkan dongeng melalui gawai dalam pelbagai bahasa tanpa harus menunggu orang tua bercerita kepada mereka. Dalam hal ini membuat interaksi orang tua dan anak menurun, hal demikian membuat kemampuan motorik dan kecakapan hidup tidak terlatih sejak dini, dan akhirnya membuat life skills seorang anak tidak berkembang. Tujuan kegiatan memperkenalkan Bahasa Inggris serta life skill kepada anak melalui pelatihan kegiatan bercerita untuk orang tua wali murid. Kegiatan ini dilakukan Pada 7 November 2018 di sebuah TK dan melibatkan guru dan orang tua wali murid dengan cara memberikan sosialisasi kepada guru dan orang tua murid. Hasil dari kegiatan ini orang tua wali murid mampu melakukan kegiatan bercerita untuk anak mereka. 10 dari 30 peserta didik menunjukan kharakter yang lebih baik seperti buang sampah sendiri, mampu makan sendiri, dan berbicara lebih sopan.
\end{abstract}

Kata kunci : Bahasa Inggris,Life skills, Storytelling.

\begin{abstract}
English in globalization era become familiar language for millennial children. English use to be a delivery language in many occasions. Such gadget, sometimes it can replace habit between the parents and children, for example: before children wait their parents to listen the fairy tale or story telling from their books, nowadays They can listen the story from their gadget in various language without waiting their parents to read the story. In other way it makes the interaction between parents and children is decrease, so it makes psychomotor and life skill of children are not develop. Life skills are important to be had by early age, by having life skills, can help children to face the challenge in their life. This activity is aim to introduce English and life skill through story telling activity to teachers and parents. This activity was held at $7^{\text {th }}$ of November 2018 at kindergarten which involved teachers and parents. The results of this activity are the parents could do story telling activity, and 10 from 30 students have increases in their soft skill, for example: they can throw the rubbish into rubbish bin, feed them self, speak politely.
\end{abstract}

Keywords: English, life skills, Storytelling.

Correspondence author: Fitria Iswari, fitriaiswari@gmail.com, Jakarta, Indonesia

This work is licensed under a $C C-B Y-N C$ 


\section{PENDAHULUAN}

Di era globalisasi seperti saat ini dapat memberikan dampak yang positif dan dampak yang negatif sekaligus apabila orang tua tidak bijak dalam penggunaan segala jenis perangkat canggih atau sering disebut gadget. Tak sedikit peran gadget mampu menggantikan kebiasaan yang sering dilakukan orang tua dengan anak, contohnya: dahulu anak menunggu orang tua untuk dibacakan dongeng atau cerita sebelum tidur dengan buku - buku bacaan mereka, sekarang ini mereka bisa mendengarkan dongeng melalui gadget dalam berbagai bahasa tanpa harus menunggu orang tua bercerita kepada mereka. Dalam hal ini membuat interkasi orang tua dan anak menurun. Pendidikan kecakapan hidup (life skills) sangat penting dimiliki oleh anak sejak usia dini, memiliki kecakapan hidup diharpkan mampu mebantu anak-anak dalam menghadapi segala hal di hidup mereka. Mitra pada pengabdian masyarakat kali ini adalah RA Esa Global Insani yang berada di daerah Tajurhalang Bogor. TK ini terdiri dari 4 kelas. Dari hasil wawancara baik dengan guru dan beberapa orang tua mereka menghadapi masalah terhadap anak-anak mereka, seperti anak yang masih manja, belum bisa makan sendiri, buang sampah sembarangan, malasnya membaca, dan lebih suka menonton tv atau bermain games di gadget, masih banyak anak yang belum mengenal Bahasa Inggris, dan ketidak mampuan orang tua dalam melakukan kegiatan bercerita. Berdasarkan latar belakang permasalahan tersebut kegiatan abdimas ini bertujuan memberikan pelatihan kegiatan bercerita kepada orangtua wali yang berisi pengenalan Bahasa Inggris serta life skill kepada anak melalui, yang dimana hasilnya diharapkan mampu membentuk life skill peserta didik yang jauh lebih mandiri dan berkharakter, dan para orang tua yang mampu melakukan kegiatan story telling di rumah.

Dalam hal ini baik orang tua maupun guru harus memeliki cara agar para siswa memiliki kecapakan hidup agar lebih siap menghadapi segala tantangan yang akan mereka hadapi dalam hidup serta terbiasa mengenal bahasa Inggris agar mampu mengikuti perkembangan zaman yang sangat cepat. Kegiatan bercerita ini (story telling) ini penting dilakukan sejak usia dini yaitu usia tumbuh kembang anak. Manfaat story telling tidak hanya dapat dirasakan oleh yang diceritakan namun juga yang menceritakan, menurut Itadz (2008) berbicara mengenai Storytelling sungguh banyak manfaatnya. Tak hanya bagi anak-anak tetapi juga bagi orang yang mendongengkannya. Dan manfaat Storytelling diantaranya: 1) membantu pembentukan pribadi dan moral anak, 2) menyalurkan kebutuhan imajinasi dan fantasi anak, 3) memacu kemampuan verbal anak, 4) merangsang minat menulis dan membaca anak, 5) membuka cakrawala pengetahuan anak.

Target Luaran dalam kegiatan abdimas ini adalah sebuah penyuluhan dan pelatihan bercerita dan buku cerita berbahasa Inggris yang dicetak dan dibagikan kepada orang tua murid. Judul cerita yang dipublikasikan adalah tentang kehidupan sehari hari yang member nilai moral yang positif seperti, 1) Aku bisa makan sendiri, 2) Aku anak yang santun. Dengan tokoh anak TK laki-laki yang bernama Danish. Dengan bantuan cerita ini diharapkan mampu menjadi solusi bagi permasalahan para orang tua dan guru.

\section{METODE PELAKSANAAN}

Waktu kegiatan mulai dari perencanaan, persiapan, pelaksanaan, hingga penyusunan laporan berlangsung mulai dari Juli 2018 sampai dengan November 2018. 
Pelaksanaan kegiatan berupa workshop mengenai pengenalan bahasa Inggris dan Kecakapan hidup (life skills) yaitu pada hari Rabu, 7 November yang berlokasi di RA Esa Global Insani yang berlokasi di Tajur Halang Kabupaten Bogor. Metode pelaksanaan dibagi dalam lima tahap, yaitu:

1. Tahap Komunikasi

Setelah menyepakati lokasi serta mitra yang akan diajak bekerjasama, anggota mulai melakukan koordinasi dengan mitra agar terjalin komunikasi yang harmonis agar tercapainya target luaran. Tim pelaksana memastikan kegiatan ini adalah bagian dari Tri Darma perguruan Tinggi serta menjamin bahwa kegiatan ini diberikan oleh narasumber yang berkompeten dibidangnya. Tim pelaksana melakukan koordinasi baik melalui telepon atau tatap muka demi kelancaran kegiatan, sehingga mendapatkan surat persetujuan kesediaan mitra.

2. Tahap pengumpulan observasi dan pengumpulan data.

Dalam tahap ini tim melakukan observasi dengan cara melakukan wawancara kepada orang tua murid dan murid guna mendapatkan data yang berguna untuk kegiatan Abdimas nantinya. Tim melakukan observasi tempat yang akan digunakan untuk kegiatan untuk dapat menyiapkan alat-alat yang diperlukan pada saat kegiatan berlangsung.

3. Tahap Persiapan Kegiatan

Tim pelaksana menyiapkan materi seperti, cerita dalam berbahasa inggris yang akan dibagikan kepada guru dan orang tua murid, dan mencetak cerita tersebut, mempersiapkan slide presentasi untuk acara workshop pengenalan bahasa Inggris dan life skills dengan cara bercerita (story telling) pada tingkat anak usia dini di TK.

4. Tahap Pelaksanaan Kegiatan

Tim Pelaksana melakukan kegiatan Pengabdian kepada Masyarakat di lokasi, yang melibatkan 5 orang guru dan 20 orang tua murid yang akan dilaksanakan pada 7 November 2018. Setelah dilakukan kegiatan abdimas maka dilanjutkan dengan evaluasi terhadap kegiatan pengabdian kepada masyarakat.

5. Tahap Penyusunan Laporan

Tim pelaksana membuat laporan kegiatan pengabdian kepada masyarakat dan laporan Akhir.

\section{HASIL DAN PEMBAHASAN}

Target yang direncanakan dalam kegiatan pengabdian masyarakat kali ini adalah pengenalan serta pelatihan kegiatan bercerita untuk orang tua wali murid dengan mengenalkan bahasa Inggris dan pengetahuan tentang kecakapan hidup (life skilsl). Hasil dari kegiatan bercerita ini memberikan dampak baik yaitu sekitar 10 anak dari 30 anak menunjukan kharakter yang lebih baik seperti buang sampah sendiri, mampu makan sendiri, dan berbicara lebih sopan. Seperti yang sudah dijelaskan di atas solusi yang kami tawarkan kepada mitra dimaksudkan dengan cara memberi pengenalan bahasa Inggris dan kecakapan hidup (life skill) sejak usia dini. Hal ini dilakukan dengan dasar bercerita adalah suatu kegiatan yang dilakukan seseorang secara lisan kepada orang lain dengan 
alat tentang apa yang harus disampaikan dalam bentuk pesan, informasi atau hanya sebuah dongeng yang dikemas dalam bentuk cerita yang dapat didengarkan dengan rasa menyenangkan seperti yang diungkapkan Madyawati, (2016). Kegiatan bercerita ini (story telling) ini penting dilakukan sejak usia dini yaitu usia tumbuh kembang anak. Manfaat story telling tidak hanya dapat dirasakan oleh yang diceritakan namun juga yang menceritakan, menurut Itadz (2008) berbicara mengenai Storytelling sungguh banyak manfaatnya. Tak hanya bagi anak-anak tetapi juga bagi orang yang mendongengkannya. Dan manfaat Storytelling di antaranya: 1) membantu pembentukan pribadi dan moral anak, 2) menyalurkan kebutuhan imajinasi dan fantasi anak, 3) memacu kemampuan verbal anak, 4) merangsang minat menulis dan membaca anak, 5) membuka cakrawala pengetahuan anak.

Kegiatan pengabdian kepada masyarakat dilakukan di RA Esa Global Insani dengan melakukan kegiatan perancangan buku cerita dalam bahasa Inggris dan penyuluhan tentang kegiatan bercerita dan pentingnya lifeskill bagi anak. Pada kegiatan ini dihadiri oleh orang tua murid dan guru RA Esa Global Insani pada hari Rabu, 7 November 2018.

\section{Pengenalan Berbahasa Inggris melalui buku cerita berbahasa Inggris} tahap, yaitu:

Dalam kegiatan ini buku yang dirancang oleh tim dosen memerlukan beberapa

1. Penyusunan naskah, penyusunan naskah dalam 2 bahasa yaitu bahasa Inggris dan ahasa Indonesia yang membutuhkan waktu satu minggu. Penyusun naskah dalam buku ini ialah fitria iswari. Setelah naskah dibuat kemudian di susun

2. Pembuatan Ilustrasi secara manual. Yaitu dengan menggambar secara manual kemudian diselesaikan dengan pewarnaan dengan menggunakan cat air.

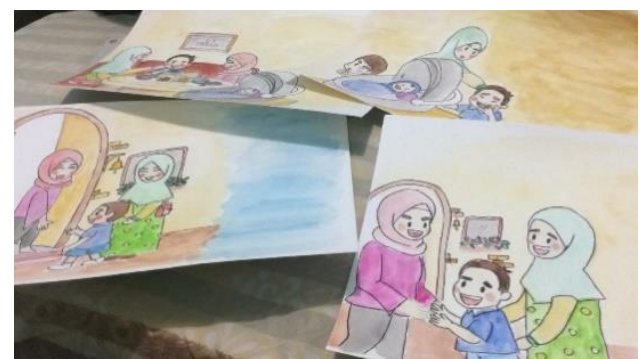

Gambar 1. Ilustrasi cerita dibuat manual dengan pensil warna

3. Setelah selesai tahap pembuatan ilustrasi dilanjutkan dengan tahap pemindaian gambar, lalu dilakukan pengeditan di komputer dengan program photoshop dan painting untuk diberi naskah cerita.

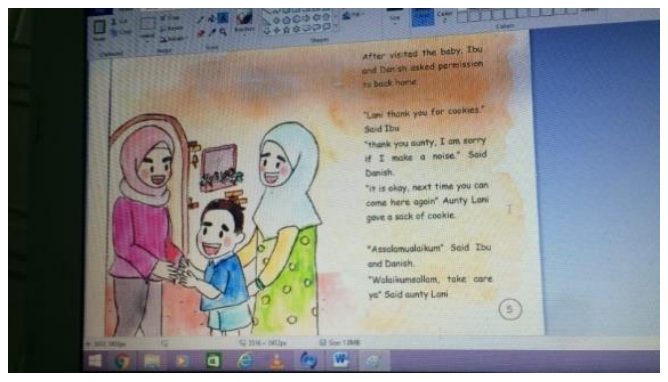

Gambar 2. Pemberian naskah pada ilustrasi 
4. Setelah selesai dipindai, teks tersebut dicetak dan siap dibagikan kepada orang tua murid RA Esa Global Insani pada saat kegiatan pengenalan bahasa Inggris dan kecakapan hidup (life skill) melalui kegiatan bercerita pada anaka usia dini di R.A Esa Global Insani

Buku cerita ini dicetak dalam bentuk satu buku namun terdapat 2 cerita di dalamnya. Buku ini tertulis dalam bahasa Inggris dan bahasa Indonesia. terjemahan bahasa Indonesia terdapat di akhir cerita pada buku tersebut. Buku yang dibuat terpisah antara bahasa Inggris dan bahasa Indonesia ini agar memudahkan para orang tua dan anak dalam membaca buku tersebut. bahasa Inggris yang digunakan adalah bahasa yang ringan dan pendek, dan apabila dibacakan secara teratur akan mudah diingat oleh anak, dan hal ini mampu menambah kosakata bahasa Inggris anak.

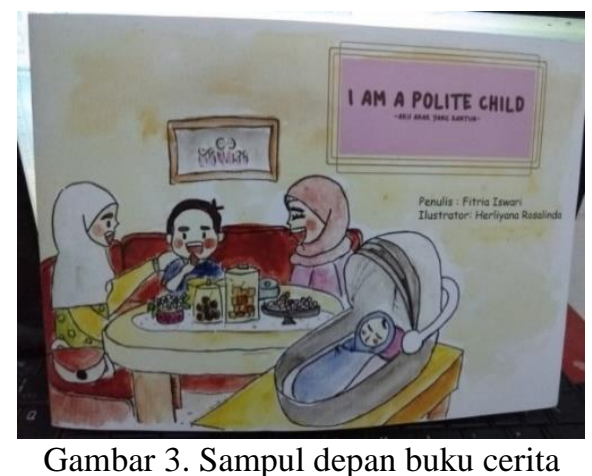

Dalam buku yang berjudul "Aku Bisa Makan Sendiri” terdapat 4 halaman di dalamnya. Buku yang bercerita tentang Danish anak TK yang berusia 5 tahun yang belajar makan sendiri tanpa bantuan orang tua. Buku ini menceritakan Danish yang hendak ke sekolah dan harus melewati serangkaian kegiatan yang selain mengenalkan life skill juga memeberikan nilai moral seperti terbiasa bangun pagi dan sarapan pagi, membiasakan makan sayur, tidak berisik atau memainkan alat makan saat sedang makan. Dalam pemilihan kharakter disesuaikan dengan murid TK yang menjadi mitra agar anak-anak merasa Danish adalah sosok teman sama seperti anak murid tk lainnya, sehingga mudah untuk dicontoh.

Sementara buku yang berjudul aku anak "Aku Anak yang Santun" terdapat 8 halaman di dalamnya. Buku ini bercerita tentang Danish dan Ibunya yang berkunjung ke rumah Tante Lani teman Ibu yang baru saja melahirkan seorang bayi. Dalam buku ini banyak sekali nilai moral untuk anak yang dapat dicontoh apabila berkunjung ke rumah orang lain, seperti, memakan makanan yang dihidangkan setelah ditawarkan, makan tidak terburu-buru, dan tidak membuat gaduh di rumah orang lain. Oleh karena itu buku ini dapat membantu orang tua murid untuk memperkenalkan life skill kepada anak mereka. 


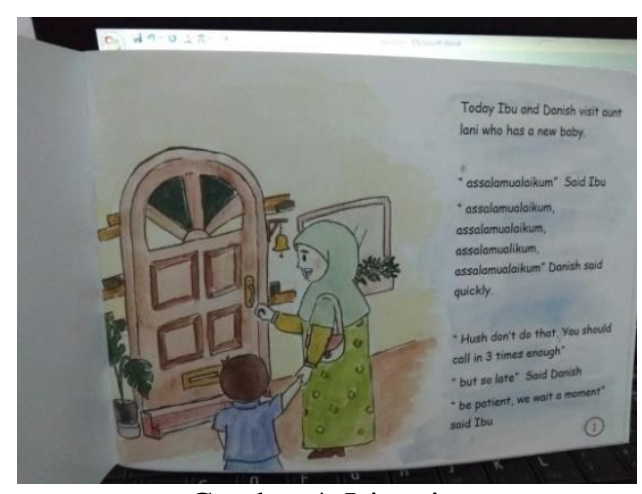

Gambar 4. Isi cerita

\section{Penyuluhan dan Pelatihan mengenai pendidikan kecakapan hidup (life skill) melalui kegiatan story telling}

Pada kegiatan abdimas tersebut sekitar $80 \%$ orang tua tidak tahu tentang penting dan manfaat mengenai kecakapan hidup (life skill). Banyak anak mereka yang tidak dilatih tentang kecakapan hidup. Masih banyak anak yang tidak mau membawa tas sekolah mereka sendiri, disuapi, bahkan masih ada yang tidak bisa memakai sepatu sendiri. Penyuluhan ini diberikan bertujuan untuk para orang tua agar mampu melatih anaknya untuk memiliki kecakapan hidup (life skill) yang baik, hal ini bertujuan untuk menyiapakan kemandirian anak dalam kehidupan.

Dalam kegiatan ini tim dosen memberikan informasi bagaimana melakukan story telling terhadap anak usia TK. Adapun cara melakukan story telling, yaitu: 1) membaca dengan lantang dan disertai artikulasi yang jelas. hal ini bertujuan agar anak mampu menangkap cerita dengan jelas, 2) gunakan ekspresi yang sesuai, 3) beri kesempatan anak untuk bertanya di sela-sela waktu bercerita, 4) bacakan buku cerita dalam keadaan rileks, 5) boleh gunakan alat bantu bercerita seperti boneka.

Setelah mencotohkan cara bercerita yang baik Tim Dosen informasi mengenai pentingnya life skill dalam kehidupan anak. Selain itu juga diadakan sesi diskusi dimana orang tua bias menanyakan beberapa pertanyaan mengenai kegiatan bercerita dan life skill kepada tim abdimas, dan di akhir kegiatan ini beberapa para orang tua mempraktekan bagaimana melakukan kegiatan bercerita dan mereka semua tampak sangat antusias. Dalam hal ini mitra sangat terbantu dan mendapatkan banyak informasi yang bermafaat bagi orang tua murid.

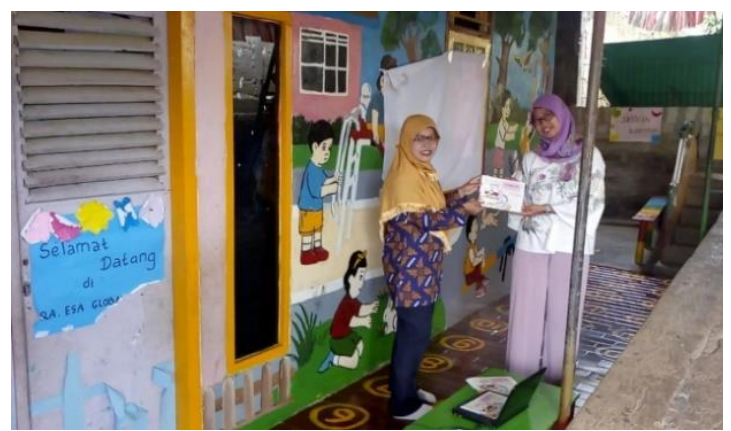

Gambar 5. Orangtua mempraktekan bagaimana melakukan story telling

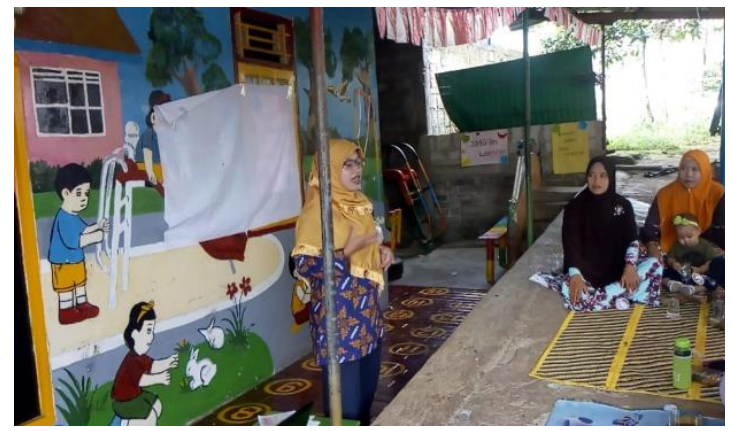

Gambar 6. Pemberian materi berupa pengenalan bahasa Inggris dan kecakapan hidup melalui kegiatan story telling 


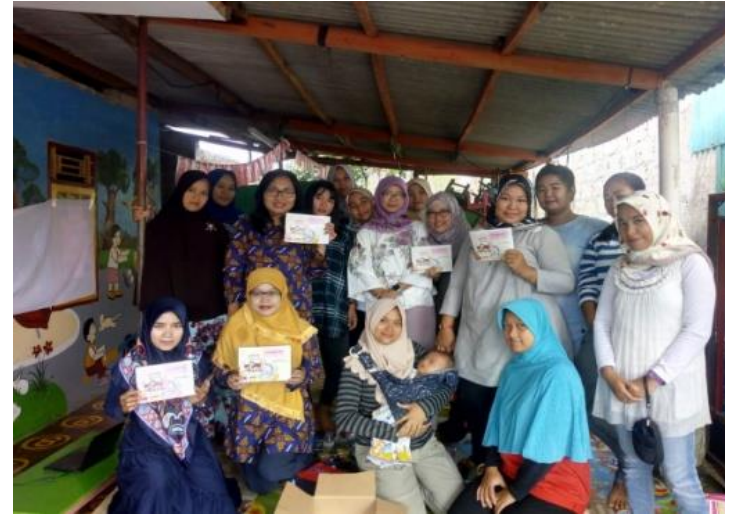

Gambar 7. Partisipasi orang tua dalam kegiatan Abdimas

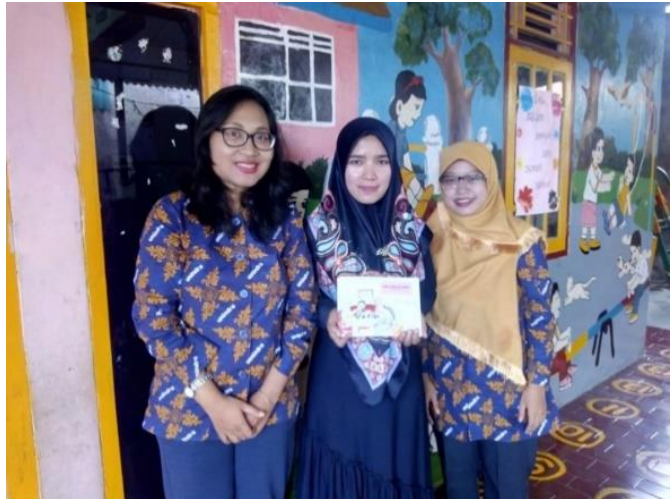

Gambar 8. Penyerahan hasil luaran kepada Kepala sekolah

\section{SIMPULAN}

Simpulan kegiatan pengabdian kepada masyarakat ini banyak diambil mafaatnya baik oleh tim dan mitra. Berikut kesimpulan yang dari kegiatan pengabdian kepada mengenai pengenalan bahasa Inggris dan kecakapan hidup (life skill) melalui kegitan bercerita, yaitu, 1) buku cerita berbahasa Inggris mampu membantu para orang tua murid dalam mengenalkan bahasa Inggris sejak dini, disertai dengan penggunaan kosakata yang ringan sehingga mampu diingat oleh anak, 2) penggunaan buku cerita dalam kegiatan bercerita dapat menjadi alat sebagai pengenalan kecakapan hidup (life skill) sejak dini, karena dalam cerita banyak terkandung nilai moral yang baik, 3) banyak orang tua yang tidak tahu tentang pentingnya kecakapan hidup (life skill) bagi anak-anak mereka supaya membentuk anak yang mandiri, 4) banyak orang tua yang tidak tahu manfaat bercerita, karena sebagian dari anak mereka lebih sering diperkenalkan dengan gawai, dikarenakan orang tua sibuk dengan pekerjaan rumah.

Adapun saran setelah kegiatan ini ialah, 1) RA Esa Global Insani sebaiknya memfasilitasi orang tua mengenai kegiatan bercerita supaya orang tua mendapat ilmu dan mampu mempraktekan di rumah, 2) orang tua mulai membiasakan kegitan bercerita di rumah dengan mensisipkan nilai moral, melatih berbahasa Inggris anak, dan melatih life skill anak.

\section{DAFTAR PUSTAKA}

Anwar. (2012). Pendidikan kecakapan hidup (life skill education). Bandung: Alfabeta.

Aqib, Z. (2009). Penelitian Tindakan Kelas (PTK) untuk guru SD, SLB, TK. Bandung: Yrama Widya.

Itadz. (2008). Memilih, menyusun, dan menyajikan cerita untuk anak usia dini. Yogyakarta: Tiara Wicana

Madyawati, L. (2016). Strategi pengembangan bahasa pada anak. Jakarta: Prenadamedia Group. 